\title{
Antigenic and molecular characterization of Vibrio ordalii strains isolated from Atlantic salmon Salmo salar in Chile
}

\author{
Andrés Silva-Rubio ${ }^{1}$, Claudia Acevedo ${ }^{1}$, Beatriz Magariños ${ }^{2}$, \\ Beltrán Jaureguiberry ${ }^{1}$, Alicia E. Toranzo ${ }^{2}$, Ruben Avendaño-Herrera ${ }^{1, *}$ \\ ${ }^{1}$ Laboratorio de Veterquímica, Camino a Melipilla 5641, Cerrillos, Santiago, Chile \\ ${ }^{2}$ Departamento de Microbiología y Parasitología, Facultad de Biología e Instituto de Acuicultura, Universidad de Santiago, \\ 15782 Santiago de Compostela, Spain
}

\begin{abstract}
Biochemical, serological and molecular properties of a group of 14 Vibrio ordalii strains isolated from cultured Atlantic salmon Salmo salar in Chile in recent years were studied. The characteristics of isolates were compared with the type strain $V$. ordalii ATCC $33509^{\mathrm{T}}$. The Chilean $V$. ordalii represented a biochemically homogenous group; however, some minor differences with the type strain were observed. The serological relationships among isolates, as well as the study of their antigenic determinant (LPS) revealed a strong reaction with antisera raised against Atlantic salmon strains and the antiserum raised against Listonella anguillarum serotype O2. However, LPS electrophoretic patterns were completely different from the $V$. ordalii type strain, regardless of the serum employed, suggesting the possibility that the Chilean strains constitute a new serological subgroup within this bacterial species. Genetic analyses by PFGE, RAPD, REP-PCR and ERIC-PCR demonstrated that all $V$. ordalii strains were genetically homogenous, displaying similar DNA patterns, regardless of the techniques used. Moreover, the analysis of DNA banding patterns generated by ERIC-PCR and REP-PCR also clearly separated the type strain from the Chilean strains. This is the first report of characterization of $V$. ordalii strains from the Southeastern Pacific area, the results of which should facilitate the development of vaccines for protecting cultured Atlantic salmon against vibriosis in this area.
\end{abstract}

KEY WORDS: Vibrio ordalii $\cdot$ Fish vibriosis $\cdot$ Serotyping $\cdot$ Genotyping $\cdot$ Atlantic salmon

\section{INTRODUCTION}

Vibriosis is one of the major diseases occurring in marine and brackish fish culture and is characterized by hemorrhagic septicemia. Although Listonella anguillarum is regarded as the dominant species causing vibriosis, several Vibrio species are also implicated in disease problems in mariculture (Toranzo \& Barja 1993, Toranzo et al. 2005).

Vibrio ordalii, formerly Listonella anguillarum biovar II (Schiewe et al. 1981), was isolated for the first time from diseased salmon cultured in coastal waters of America's Pacific Northwest (Harrel et al. 1976). Since its first isolation, $V$. ordalii has been also reported in Japan, Australia and New Zealand, affecting mainly the culture of several salmonid species (Ransom et al. 1984, Toranzo et al. 1997). Although salmon farming is a significant industry in Chile, surprisingly, no cases of vibriosis were noted in marine salmonid aquaculture until 2004, when disease outbreaks associated with moderate mortalities ( $8.2 \%$ ) in populations of Atlantic salmon Salmo salar cultured in southern Chile were reported (Colquhoun et al. 2004).

Numerous studies describe Vibrio ordalii as a biochemically and serologically homogeneous taxon (see review Toranzo et al. 1997, 2005). Recent studies 
(Colquhoun et al. 2004) using conventional methods and miniaturized systems have demonstrated that Chilean $V$. ordalii isolates share the same biochemical properties present in the previous description of the species (Schiewe et al. 1981), with the exception of production of acid from trehalose and lack of acid production from mannitol. In addition, these Chilean strains could not be serotyped due to auto-agglutination of the isolates (Colquhoun et al. 2004).

However, until now, no discriminative methods based on genetic techniques have been applied to this bacterium. Pulsed-field gel electrophoresis (PFGE) (Skov et al. 1995), randomly amplified polymorphic DNA (RAPD)-PCR, enterobacterial repetitive intergenic consensus sequence (ERIC)-PCR and repetitive extragenic palindromic (REP)-PCR have become accessible and sensitive methods for the intraspecific genetic variability in many pathogens (Williams et al. 1990, Versalovic et al. 1991, Bachellier et al. 1999). Therefore, the objective of this study was to describe in depth the biochemical and antigenic characteristics of the Vibrio ordalii strains isolated from disease outbreaks in Salmo salar in Chile, for future development and/or improvement of the vaccination program against vibriosis. In addition, PFGE and 3 PCR-based methods were employed to analyse the genetic variability among the $V$. ordalii strains, with the aim to evaluate this technique as a useful epidemiological tool for this pathogen.

\section{MATERIALS AND METHODS}

Bacterial strains and growth conditions. Fourteen Vibrio ordalii strains isolated from Atlantic salmon Salmo salar from 5 different salmon farms and 2 locations on and near Chiloe Island, Chile, during 2003-2005 were used in the present study (Table 1). These strains were confirmed as $V$. ordalii by sequencing of the 16S rRNA using ABI PRISM Kit reaction and ABI PRISM 310 sequencer (Applied Biosystems) according to the manufacturer's recommendations. These sequences were aligned and compared with sequences of the type strain of $V$. ordalii ATCC $33509^{\mathrm{T}}$ (X74718) and $V$. ordalii strain 2003/09/511-2063 (AY530930) obtained from GenBank.

In all studies, the type strain of Vibrio ordalii ATCC $33509^{\mathrm{T}}$ from the American Type Culture Collection was used for comparative purposes. The type strains of Listonella anguillarum ATCC 43305 (serotype O1), ATCC 43306 (serotype O2) and ATCC 43307 (serotype O3) were also included in the dot-blot and westernblot assays. All strains were routinely cultivated on/in Luria Bertani (LB) agar or broth supplemented with $1.5 \%(\mathrm{w} / \mathrm{v})$ sodium chloride and incubated at $20^{\circ} \mathrm{C}$ for
$72 \mathrm{~h}$. Stock cultures were maintained frozen at $-70^{\circ} \mathrm{C}$ in LB broth containing $1.5 \% \mathrm{NaCl}$ and $15 \%$ (v/v) glycerol.

Biochemical and physiological characterization. The strains were examined using phenotypic tests basically as reported by MacFaddin (1984). In addition, the miniaturized API 20E system (bioMèrieux) was also employed. Biochemical profiles of our isolates were compared with those of the Vibrio ordalii type strain.

Serological characterization. Based on the biochemical homogeneity of the bacterium, antisera against 3 representative strains isolated from Atlantic salmon, coded as Au2, Au3 and PF180, were prepared by intravenous injections of rabbits as described by Sørensen \& Larsen (1986). Before the serological assays, the titer of each immune serum was determined by an ELISA. In addition, to evaluate the antigenic cross-reactivity among Vibrio ordalii and Listonella anguillarum serotype O2, all serological tests were conducted using a polyclonal antiserum raised against the type strain ATCC 43306 (serotype O2). The serological analyses were performed with unabsorbed and absorbed rabbit serum. For absorption, the antisera against isolates Au2, Au3 and PF180, as well as serum against $L$. anguillarum serotype $\mathrm{O} 2$, were mixed with the antigens of the homologous and heterologous isolates and incubated overnight at $4^{\circ} \mathrm{C}$. This process was repeated twice to ensure a complete absorption of common antigens.

Slide agglutination tests were conducted to examine the serological relationship between strains (Toranzo et al. 1987). The dot-blot analysis was performed as described by Cipriano et al. (1985). Only a reaction similar to that exhibited by the homologous strain was scored as positive.

Preparation of lipopolysaccharides, membrane proteins and immunoblotting analysis. LPS from the cell envelope were obtained by the Proteinase $\mathrm{K}$ method following the procedures of Hitchcock \& Brown (1983). Samples were examined by sodium dodecyl sulfate-polyacrylamide gel electrophoresis (SDS-PAGE; Laemmli 1970) and then silver stained by the procedure of Tsai \& Frasch (1982).

The cell envelope proteins from the Vibrio ordalii strains were prepared from bacterial culture grown in LB broth as described by Avendaño-Herrera et al. (2004) and examined by SDS-PAGE as described for the LPS analyses. After electrophoresis proteins were stained with $0.05 \%$ Coomassie blue R (Sigma), photographed, and the relative mobilities of each one were determined by comparison with standard protein markers (Winkler).

Cell envelope components (LPS and proteins) separated by SDS-PAGE were transferred onto nitrocellulose membranes by electrophoretic blotting accord- 


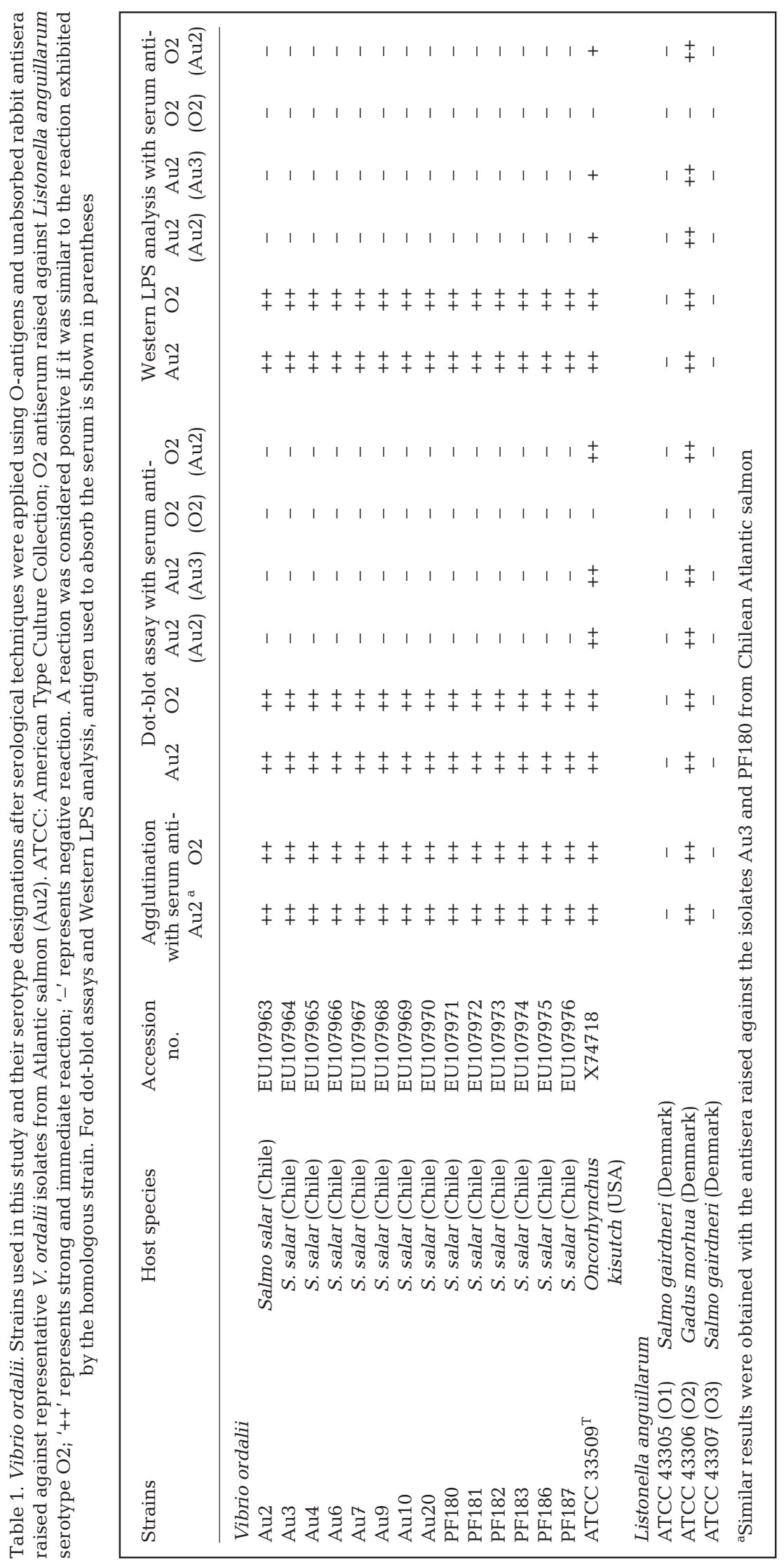

ing to procedures of Towbin et al. (1979), and subjected to immunological analysis as outlined above for the dot blot assay.

Genetic characterization. PFGE analysis. The PFGE analyses were performed using the NotI (Invitrogen) enzyme according to the methods described by Vela et al. (2003). The running conditions were $6 \mathrm{~V} \mathrm{~cm}^{-1}$ at $14^{\circ} \mathrm{C}$ for $24 \mathrm{~h}$ at a field angle of $120^{\circ}$, and switch times were 1 to $18 \mathrm{~s}$ for $12 \mathrm{~h}$ and 3 to $80 \mathrm{~s}$ for $12 \mathrm{~h}$. Following electrophoresis, the gels were stained with ethidium bromide $\left(0.5 \mu \mathrm{g} \mathrm{ml}^{-1}\right)$ for $30 \mathrm{~min}$, destained in distilled water for $1 \mathrm{~h}$, and visualised with a UV trans-illuminator. The molecular sizes of the fragments obtained were estimated using the GelComparII Software (Applied Maths BVBA), and the DNA of Saccharomyces cervisiae YN295 and Vibrio parahaemolyticus RIMD 2210856 cleaved by NotI were used as molecular size markers.

DNA extraction: Chromosomal DNA was purified from cell lysates. For the preparation of cell lysates, overnight cultures of the bacteria were centrifuged at $10000 \times g$ for 5 min, resuspended in a lysis solution (SDS 1\%; NaCl $0.15 \mathrm{M}$; EDTA $1.25 \mathrm{mM} \mathrm{pH}$ 8.0; Tris- $\mathrm{HCl} 0.1 \mathrm{M}$ $\mathrm{pH}$ 7.5) and heated at $100^{\circ} \mathrm{C}$ for 10 min. Samples were then treated with Proteinase $\mathrm{K}$ solution (10 mg $\mathrm{ml}^{-1}$ ) and incubated at $60^{\circ} \mathrm{C}$ for $30 \mathrm{~min}$ followed by 2 sequential chloroform-phenol extraction and ethanol precipitation steps. DNA was also extracted using InstaGene Purification Matrix (Bio-Rad Laboratories) according to the manufacturer's protocols. The concentration of DNA was visually estimated after agarose gel electrophoresis of $2 \mu \mathrm{l}$ of sample, and all DNA solutions were adjusted with sterile distilled water so that reaction could be performed on similar amounts of DNA (concentration of 10 to $20 \mathrm{ng}$ $\mu^{-1}$ ). All experiments were carried out with DNA obtained in 2 differ- 
ent extractions for each bacterial strain. Extracted DNA was maintained at $-20^{\circ} \mathrm{C}$ until used for PCR reactions. We used $1 \mu \mathrm{l}$ of each DNA solution in the respective amplification reaction.

ERIC-PCR, REP-PCR and RAPD-PCR typing: The ERIC-PCR, REP-PCR and RAPD-PCR amplifications were done using commercial Ready-To-Go ${ }^{\mathrm{TM}}$ PCR beads (Amersham Pharmacia Biotech). All PCR amplifications were carried out in a T Gradient thermocycler (Biometra) and the specific primers for each assay, as well as the amplification protocols employed for each technique, were those described by Mancuso et al. (2007). In addition, in order to determine whether the ERIC and REP sequences were actually present in the genome of Vibrio ordalii or whether the PCR amplicons obtained were random products due to nonspecific amplifications, DNA extracted from strain $V$. ordalii ATCC $33509^{\mathrm{T}}$ and Escherichia coli K512 were used for annealing temperature gradient assays of ERIC-PCR and REP-PCR. For ERIC-PCR amplifications, the annealing temperature gradient ranged from 52 to $66^{\circ} \mathrm{C}$ and from 40 to $64^{\circ} \mathrm{C}$ for REP-PCR.

All PCR products were separated by horizontal electrophoresis on a $1.5 \%$ (w/v) agarose gel, visualized with ethidium bromide (Bio-Rad) and photographed under UV light. A 100-bp DNA ladder (Invitrogen) was used as molecular mass marker. In all cases, negative controls, consisting of the same reaction mixture but with sterile distilled water instead of template DNA, were included in each batch of PCR reactions. In order to determine significant differences in the patterns, reproducibility of results was assessed by repetition in at least 2 independent assays.

Computer data analysis. All gels were scanned and the images captured by a Gel Doc-2000 gel documentation system (Bio-Rad). The data analysis was performed using the Diversity Database software (BioRad), and the computed similarities among strains were estimated by means of the Dice coefficient $\left(S_{d}\right)$ (Dice 1945). A dendrogram was produced on the basis of the unweighted average pair group method (UPGMA).

\section{RESULTS AND DISCUSSION}

\section{Biochemical characterization}

The phenotypic tests showed that all bacterial isolates were Gram-negative, rods, motile, fermentative, produced catalase and cytochrome oxidase, and were sensitive to the vibriostatic compound O/129, all of which are typical characteristics of marine vibrios. The utilization of the miniaturized API 20E kit rendered for all the isolates the same profile 0004024. All Vibrio ordalli isolates studied were phenotypically similar to the profile reported by Colquhoun et al. (2004), with the exception that these authors found that 1 of 3 strains were gelatinase-negative while all our strains failed to hydrolyse gelatin. The type strain showed the pattern 0006124, which is in accordance with the biochemical description made by Schiewe et al. (1981) for this species using conventional tube and plate test procedures.

\section{Serological characterization}

To examine the antigenic properties of the Chilean isolates, we selected 3 Vibrio ordalii strains to obtain immune serum for rabbit; the homologous titers of these antisera varied between 2048 and 8192 .

The slide agglutination assays using the Vibrio ordalii antisera and O-antigens revealed cross-reactions for all strains regardless of the host origin and serum employed (Table 1). These findings indicate that all $V$. ordalii strains isolated from Atlantic salmon may be serologically homogeneous. In agreement with Mutharia et al. (1993) and Larsen et al. (1994), all V. ordalii strains included in this study showed a strong reaction with the serotype $\mathrm{O} 2$ antiserum of Listonella anguillarum. However, when phosphate buffered saline was used instead of each antiserum in the slide agglutination assays, no auto-agglutination was detected (data not shown), as previously described by Colquhoun et al. (2004).

When the dot-blot assays were performed, the 14 isolates studied and all the type strains (except Listonella anguillarum serotype O1 and O3) also showed strong reactions with antisera raised against the 3 Atlantic salmon strains and the $L$. anguillarum serotype O2 (Table 1). Interestingly, all immunological reaction towards the Chilean isolates disappeared when the $V$. ordalii antisera were absorbed with a heterologous and homologous Atlantic salmon strain, confirming that all the Chilean isolates correspond to a same serological group, while the strong antigenic reaction remained in both type strains $(V$. ordalii ATCC $33509^{\mathrm{T}}$ and L. anguillarum ATCC 43306). Similar results were observed when the $\mathrm{O} 2$ antiserum was absorbed with the heat stable O-antigen of the $V$. ordalii strains isolated from Atlantic salmon.

The result of the LPS profiling showed that all Chilean Vibrio ordalii strains displayed a similar LPS pattern with a ladder of both high-molecular-weight (HMW) and low-molecular-weight (LMW) O-antigen bands (data not shown). Although all isolates studied showed strong reaction with the antisera raised against the strains Au2, Au3 and PF180, as well as with the polyclonal antiserum $\mathrm{O} 2$, differences in the pat- 
terns were observed (Fig. 1). In fact, when the antisera raised against the Chilean $V$. ordalii isolates and the O2 antiserum were employed, reactions were only seen with the polysaccharide bands in the LMW
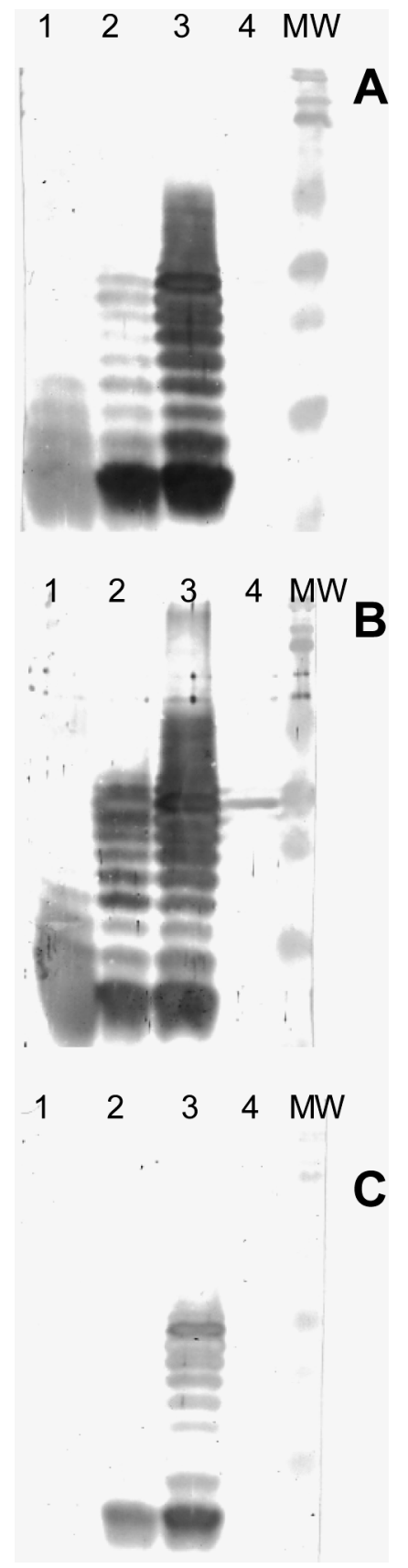

Fig. 1. Vibrio ordalii. Western-blot analyses of lipopolysaccharides of a representative Chilean $V$. ordalii strain and type strains using antisera raised against (A) Listonella anguillarum ATCC 43306; (B) Atlantic salmon Au2; and (C) O2 antiserum absorbed with an Atlantic salmon strain (isolate Au2). Lanes: MW, molecular ruler (Bio-Rad); 1, Au3; 2, ATCC $33509^{\mathrm{T}}$ ( V. ordalii); 3, ATCC 43306 (L. anguillarum O2) and 4, ATCC 43305 (L. anguillarum O1) regions in Chilean $V$. ordalii isolates, while the type strains of $V$. ordalii $\left(\right.$ ATCC $33509^{\mathrm{T}}$ ) and Listonella anguillarum (ATCC 43306) showed reaction in both LMW and HMW areas (Fig. 1A,B). These cross reactions disappeared in all $V$. ordalii isolates, with the exception of the type strain, when the $\mathrm{O} 2$ antiserum was absorbed with each $V$. ordalii strain isolated from Atlantic salmon (Fig. 1C, Table 1). Sadovskaya et al. (1998) noted that the serological cross-reactivity between $V$. ordalii and $L$. anguillarum serotype $\mathrm{O} 2$ strains may be mainly due to similar capsular structure and O-antigenic polysaccharides differing only in the degree of polymerization.

With regard to the analysis of total and outer membrane proteins, all Chilean strains presented an essentially identical profile, displaying a considerable number of common bands between 27.0 and $103.7 \mathrm{kDa}$ (Fig. 2A). These findings suggest that these isolates are a homogenous species. It is important to note that although the type strain ATCC $33509^{\mathrm{T}}$ presented a different pattern, a $40 \mathrm{kDa}$ major outer membrane protein - which corresponds to a porin conserved within bacterial species of the genus Vibrio (Davey et al. 1998) - was present in all the Vibrio ordalii strains. In addition, all proteins are antigenically related because a strong reaction was observed with the 3 sera in the western blot analysis (Fig. 2B).

Genetic characterization. PCR products sequencing of the 16S rRNA confirmed that the 14 studied isolates were Vibrio ordalii strains, identifying a $99 \%$ similarity with the type strain ATCC 33509 ${ }^{\mathrm{T}}$ (GenBank X74718) and a $99.9 \%$ similarity with the Chilean strain (accession no. AY530930). Nucleotide sequences for 16S rRNA determined in this study were deposited in GenBank under accession nos. EU107963 to EU107976 (Table 1). On the other hand, regardless of their origin, all of our isolates and the $V$. ordalii type strain ATCC $33509^{\mathrm{T}}$ were typeable, therefore, none of them failed to yield discernible amplification pattern by any of the PCR-based methods analysed.

Analysis of the restriction digest pattern resolved by endonuclease NotI showed that all Vibrio ordalii strains presented a similar PFGE pattern, consisting of 15 bands, except the strain Au3. This isolate was considered to be different because its PFGE pattern differed only in the absence of 1 band of approximately $65 \mathrm{~kb}$. Therefore, 2 groups could be differentiated with a similarity of $88 \%$ (Fig. 3). This genetic homogeneity was also observed when other $V$. ordalii strains were ribotyped, detecting the existence of 3 distinct groups with a level of similarity more than 95\% (Tiainen et al. 1995).

In recent years, the development of molecular techniques has progressed rapidly. Therefore, PCR amplification with primers specific to the repetitive genetic 


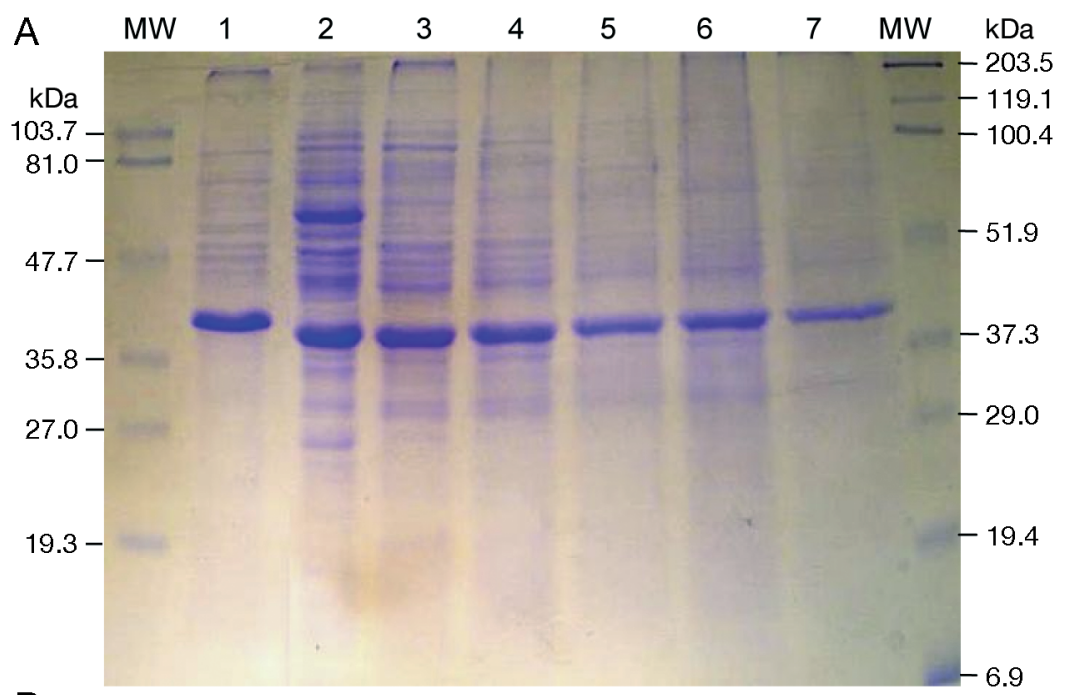

\section{$\mathrm{B}$}

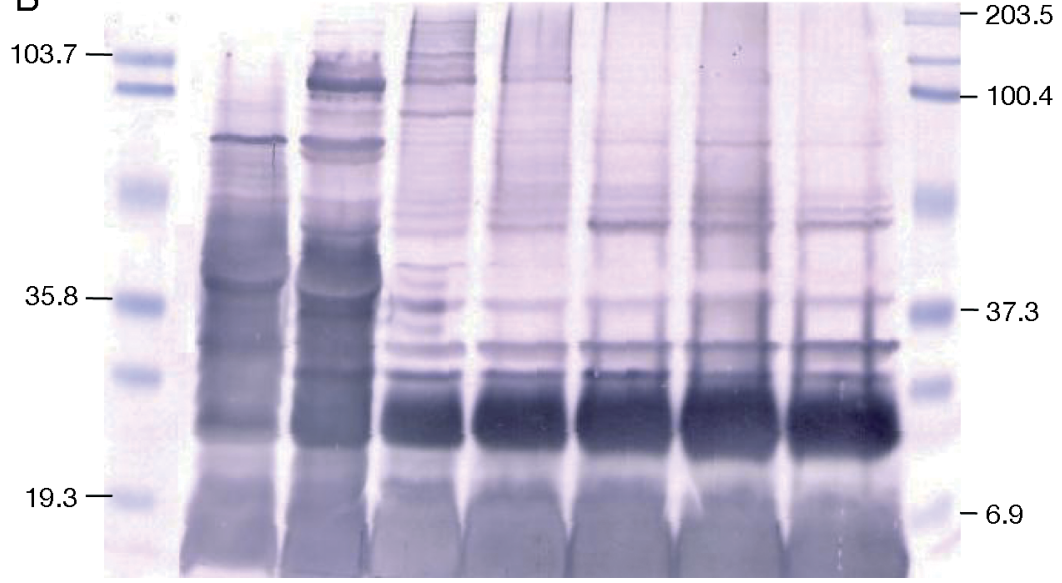

Fig. 2. (A) SDS-PAGE and (B) western blot of total membrane proteins from Chilean Vibrio ordalii isolates, and type strains of Listonella anguillarum and $V$. ordalii tested with serum directed against $V$. ordalii Au3. Lanes: MW, molecular ruler (Bio-Rad); 1, ATCC 43306 (L. anguillarum O2); 2, ATCC 33509 (V. ordalii); 3-7: Chilean V. ordalii strains

element REP and ERIC as well as RAPD analysis have been frequently used for genomic fingerprinting of Gram-negative bacteria, particularly Vibrio species, since they are fast and simple (Rivera et al. 1995a,b, Shangkuan et al. 1997, Marshall et al. 1999, Wong \& Lin 2001, Khan et al. 2002, Maluping et al. 2005, Rodríguez et al. 2006).

In our case, the analysis of the Chilean Vibrio ordalii strains and the type strain (ATCC 33509T) with ERICPCR demonstrated the existence of clonal relationships among Chilean isolates (Fig. 4C). In general, the typing of all $V$. ordalii strains consisted of at least 12 major amplification bands, ranging in size from 50 to $3000 \mathrm{bp}$. However, the $V$. ordalii type strain showed a different ERIC-PCR profile, sharing 11 of the 12 major bands present in the Chilean strains profile (Fig. 4C). It is interesting to point out that an extra band of approx- imately $800 \mathrm{bp}$ in length was shown by this isolate. When the Dice coefficient was applied, the similarity between the 2 clusters was $88 \%$.

In the case of REP-PCR the results were similar and it was evident that all strains exhibited patterns with a high number of REP-PCR products. The size of these bands ranged from 100 to 3000 bp (Fig. 4D). A difference of 2 bands was observed in the profile for the type strain ATCC $33509^{\mathrm{T}}$, which lacked a band of $490 \mathrm{bp}$ and had an additional smaller band (approximately $260 \mathrm{bp}$ ) not present in the Chilean strains, with a similarity level of $91.6 \%$.

When the RAPD technique was applied to the 14 isolates of Vibrio ordalii, only 2 oligonucleotides, P2 and P6, generated reproducible patterns with an appropriate number of amplified products suitable for an accurate analysis. When these primers were employed, only one genetic profile within the $V$. ordalii Chilean strains could be observed, regardless of the origin, yielding a similarity level of $100 \%$ to the type strain. In both cases, a total of 3 different bands were observed using the primer P2 and P6, ranging from 200 to $3000 \mathrm{bp}$ in size (Fig. 4A,B). Clearly, RAPD-PCR, ERICPCR and REP-PCR techniques did not separate the Chilean isolates as outlined above for the PFGE assays, since all strains were included in only one genetic group. Therefore, these PCRbased methods do not seem to be suitable when a high degree of discrimination is needed.

Reproducibility of RAPD, ERIC-PCR and REP-PCR results was assessed by the employment of DNA from different extractions and by repetition in at least 2 independent assays. Aside from some variations in the band intensity, no differences were observed between the profiles obtained for each strain, and all the banding patterns were highly reproducible.

\section{CONCLUSIONS}

In this work we have demonstrated that the Vibrio ordalii strains isolated from outbreaks in farmed Atlantic salmon in Region X (Chile) are biochemically, antigenically and genetically homogeneous. Interest- 


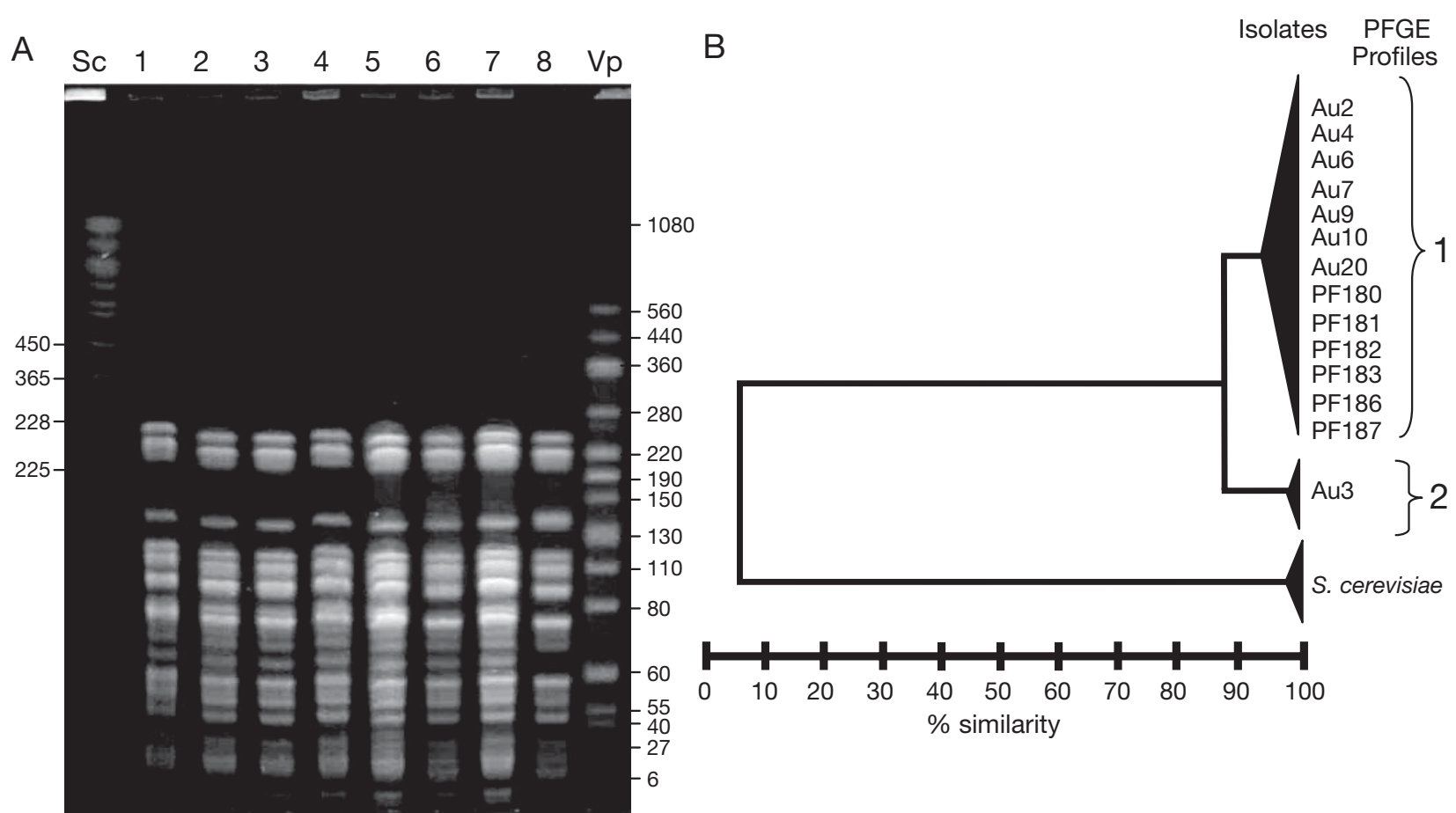

Fig. 3. Vibrio ordalii. (A) Representative PFGE pattern for $V$. ordalii strains after chromosomal DNA digestion with NotI; and (B) dendrograms illustrating the clustering of the PFGE profiles. Lanes: 1, Au2; 2, Au4; 3, Au6; 4, Au7; 5, PF180; 6, PF183; 7, PF187; 8, Au3. Undigested DNA of Saccharomyces cervisiae YN295 (Sc) and V. parahaemolyticus RIMD 2210856 (Vp) cleaved by NotI were used as molecular size markers. Numbers on left and right indicate position of molecular size marker in $\mathrm{kb}$

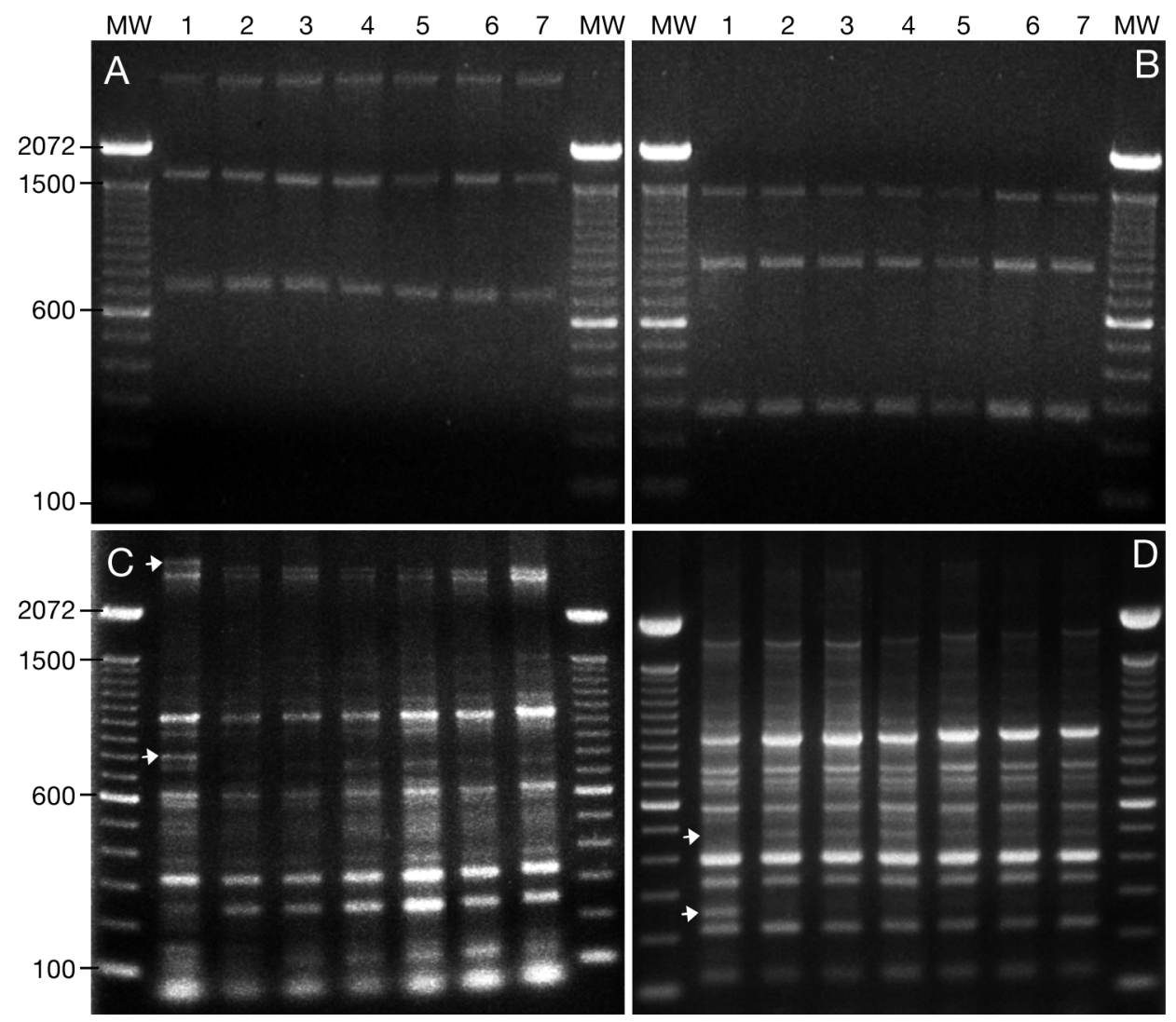

Fig. 4. Vibrio ordalii. Amplification fingerprints obtained for $V$. ordalii isolates using (A) RAPD with primer 2, (B) RAPD with primer 6, (C) ERIC-PCR and (D) REP-PCR methods. Lanes: MW, AmpliSize molecular ruler (100 bp DNA ladder, Invitrogen); 1 , ATCC $33509^{\mathrm{T}}$ (V. ordalii); and 2-7, Chilean $V$. ordalii strains. Numbers on left indicate position of molecular size marker in bp. Arrows indicate differences between amplification profile of type and Chilean strains 
ingly, the electrophoretic patterns in both LPS and proteins were different from the type strain, suggesting the possibility that the Chilean strains constitute a new serological subgroup within this bacterial species. Further studies are necessary to elucidate this question. This is the first comprehensive report of characterization of $V$. ordalii strains from the Southeastern Pacific area, the results of which should facilitate the development of vaccines for protecting cultured Atlantic salmon against vibriosis.

Acknowledgements. This work was supported by grant INNOVA-204-4044 from the Corporación de Fomento de la Producción (CORFO - Chile). R.A.H. was supported in part by Program Bicentenario Ciencia y Tecnología, CONICYT Chile. Thanks are expressed to members of the technical team of the laboratories of Veterquímica, as well as to the fish laboratories for sending the isolates. We express our gratitude to Dr. J. Fernandez (Instituto de Salud Publica, Chile) for the analysis of $16 \mathrm{~S}$ sequences. The comments and suggestions of the anonymous reviewers are greatly appreciated as they helped in improving the presentation of this work.

\section{LITERATURE CITED}

Avendaño-Herrera R, Magariños B, López-Romalde S, Romalde JL, Toranzo AE (2004) Phenotypic characterization and description of two major O-serotypes in Tenacibaculum maritimum strains from marine fishes. Dis Aquat Org 58:1-8

Bachellier S, Clément JM, Hofnung M (1999) Short palindromic repetitive DNA elements in enterobacteria: a survey. Res Microbiol 150:627-639

> Cipriano RC, Pyle JB, Starliper CE, Pyle SW (1985) Detection of Vibrio anguillarum antigen by dot blot assay. J Wildl Dis 21:211-218

Colquhoun DJ, Aase IL, Wallace C, Baklien $\AA$, Gravningen K (2004) First description of Vibrio ordalii from Chile. Bull Eur Assoc Fish Pathol 24:185-188

Davey ML, Hancock RE, Mutharia LM (1998) Influence of culture conditions on expression of the 40-kilodalton porin protein of Vibrio anguillarum serotype O2. Appl Environ Microbiol 64:138-146

> Dice LR (1945) Measures of amount of ecological association between species. Ecology 26:297

Harrel LW, Novotny AJ, Schiewe MJ, Hodgins HO (1976) Isolation and description of two Vibrios pathogenic to Pacific salmon in Puget Sound, Washington. Fish Bull (Wash DC) 74:447-449

Hitchcock PJ, Brown TM (1983) Morphological heterogeneity among Salmonella lipopolysaccharide chemotypes in silver-stained polyacrilamide gels. J Bacteriol 154:269-272

Khan AA, McCarthy S, Wang RF, Cerniglia CM (2002) Characterization of United States outbreak isolates of Vibrio parahaemolyticus using enterobacterial repetitive intergenic consensus (ERIC) PCR and development of a rapid PCR method for detection of O3:K6 isolates. FEMS Microbiol Lett 206:209-214

> Laemmli UK (1970) Cleavage of structural proteins during the assembly of the head of bacteriophage T4. Nature
227:680-685

Larsen JL, Pedersen K, Dalsgaard I (1994) Vibrio anguillarum serovars associated with vibriosis in fish. J Fish Dis 17: 259-267

MacFaddin JF (1984) Biochemical tests for identification of medical bacteria, 2nd edn. Waverly Press, Baltimore, MD

Maluping RR, Ravelo C, Lavilla-Pitogo CR, Krovacek K, Romalde JL (2005) Molecular typing of Vibrio parahaemolyticus strains isolated from the Philippines by PCRbased methods. J Appl Microbiol 99:383-391

Mancuso M, Avendaño-Herrera R, Zaccone R, Toranzo AE, Magariños B (2007) Evaluation of different DNA-based fingerprinting methods for typing Photobacterium damselae ssp. piscicida. Biol Res 39:71-82

Marshall S, Clark CG, Wang G, Mulvey M, Kelly MT, Johnson WM (1999) Comparison of molecular methods for typing Vibrio parahaemolyticus. J Clin Microbiol 37: 2473-2478

Mutharia LW, Raymond BT, deKievit TR, Stevenson RMW (1993) Antibody specificities and polyclonal rabbit and rainbow trout antisera against Vibrio ordalii and serotype O2 strains of Vibrio anguillarum. Can J Microbiol 39: 492-499

Ransom DP, Lannan CN, Rohovec JS, Fryer JL (1984) Comparison of histopathology caused by Vibrio anguillarum and Vibrio ordalii and three species of Pacific salmon. J Fish Dis 7:107-115

Rivera IG, Chowdhury MAR, Huq A, Colwell RR, Martins MT (1995a) Genomic fingerprinting of Vibrio species using ERIC primers and PCR, abstract R-10. In: Abstracts of the 95th General Meeting of the American Society for Microbiology, Washington, DC, p R-10

Rivera IG, Chowdhury MAR, Huq A, Jacobs D, Martins MT, Colwell RR (1995b) Enterobacterial repetitive intergenic consensus sequences and the PCR to generate fingerprints of genomic DNAs from Vibrio cholerae O1, O139 and non-O1. Appl Environ Microbiol 61: 2898-2904

Rodríguez JM, Lopéz-Romalde S, Beaz R, Alonso MC, Castro D, Romalde JL (2006) Molecular fingerprinting of Vibrio tapetis strains using three PCR-based methods: ERICPCR, REP-PCR and RAPD. Dis Aquat Org 69: 175-183

Sadovskaya I, Brisson JR, Khieu NH, Mutharia LM, Altman E (1998) Structural characterization of the lipopolysaccharide O-antigen and capsular polysaccharide of Vibrio ordalii serotype O:2. Eur J Biochem 253:319-327

Schiewe MH, Trust TJ, Crosa JH (1981) Vibrio ordalii sp. nova: a causative agent of vibriosis in fish. Curr Microbiol 6:343-348

Shangkuan YH, Lin HC, Wang TM (1997) Diversity of DNA sequences among Vibrio cholerae O1 and non-O1 isolates detected by whole-cell repetitive element sequencebased polymerase chain reaction. J Appl Microbiol 82: 335-344

Sørensen UBS, Larsen JL (1986) Serotyping of Vibrio anguillarum. Appl Environ Microbiol 51:593-597

Skov MN, Pedersen K, Larsen JL (1995) Comparison of pulsed-field gel electrophoresis, ribotyping, and plasmid profiling for typing of Vibrio anguillarum serovar O1. Appl Environ Microbiol 61:1540-1545

Tiainen T, Pedersen K, Larsen JL (1995) Ribotyping and plasmid profiling of Vibrio anguillarum serovar $\mathrm{O} 2$ and Vibrio ordalii. J Appl Bacteriol 79:384-392

Toranzo AE, Baya A, Roberson BS, Barja JL, Grimes DJ, Hetrick FM (1987) Specificity of slide agglutination test for detecting bacterial fish pathogens. Aquaculture 61:81-97 
Toranzo AE, Barja JL (1993) Virulence factors of bacteria pathogenic for coldwater fish. Annu Rev Fish Dis 3:5-36

Toranzo AE, Santos Y, Barja JL (1997) Immunization with bacterial antigens: Vibrio infections. In: Gudding $\mathrm{R}$, Lillehaug A, Midtlyng PJ, Brown F (eds) Developments in biologicals, Vol 90: Fish vaccinology. Karger, Basel, p 93-105

Toranzo AE, Magariños B, Romalde JL (2005) A review of the main bacterial fish diseases in mariculture systems. Aquaculture 246:37-61

Towbin H, Staehelin T, Gordon J (1979) Electrophoretic transfer of proteins from polyacrylamide gels to nitrocellulose sheets: procedure and some applications. Proc Natl Acad Sci USA 76:4350-4354

Tsai CM, Frasch CE (1982) A sensitive silver stain for detecting lipopolysaccharides in polyacrylamide gels. Anal

Editorial responsibility: Catherine Collins,

Aberdeen, UK
Biochem 119:115-119

Vela AI, Goyache J, Tarradas C, Luque I and others (2003) Analysis of genetic diversity of Streptococcus suis clinical isolates from pigs in Spain by pulsed-field gel electrophoresis. J Clin Microbiol 41:2498-2502

Versalovic J, Koeuth T, Lupski JR (1991) Distribution of repetitive DNA sequences in eubacteria and application to fingerprinting of bacterial genomes. Nucleic Acids Res 19: 6823-6831

Williams JGK, Kubelik AR, Livak KJ, Rafalski JA, Tingey SV (1990) DNA polymorphisms amplified by arbitrary primers are useful as genetic markers. Nucleic Acids Res 18: 6351-6357

Wong HC, Lin CH (2001) Evaluation of typing Vibrio parahaemolyticus by three PCR methods using specific primers. J Clin Microbiol 39:4233-4240

Submitted: May 29, 2007; Accepted: October 17, 2007 Proofs received from author(s): February 4, 2008 